\title{
Doscientos años de un periódico no tan feliz
}

Two hundred years of a not so happy newspaper

Jaime Alberto Rojas Rodríguez Candidato a magíster en Filosofia Latinoamericana, Corporación Universitaria Lasallista jaimealbertonet@yahoo.es

Artículo de investigación

Fecha de recepción: 15 de abril de 2010 • Fecha de aprobación: 18 de mayo de 2010

\section{RESUMEN}

Era ya tan relevante el periodismo hacia el final de la Colonia que una vez suscrita el Acta de Independencia, al amanecer del 21 de julio de 1810, la Junta Suprema del Nuevo Reino de Granada decidió crear un periódico para divulgar los importantes hechos relativos a la emancipación. Fue así como nació, animado por las ideas de la Ilustración, La Constitución Feliz, el 17 de agosto de 1810, con el imposible desafío de superar los dogmas del catolicismo, la filosofía escolástica y la fidelidad política a la monarquía española. El presente artículo recrea la historia de este periódico.

Palabras clave: La Constitución Feliz, independencia, periodismo.

\section{Abstract}

Journalism was so relevant at the end of the Colony that once signed the Declaration of Independence, at dawn on July 21, 1810, the Supreme Board of the New Kingdom of Granada decided to create a newspaper to divulge important facts concerning the emancipation. Thus was born, inspired by the ideas of the Enlightenment, La Constitución Feliz, on August 17, 1810, with the insurmountable challenge of overcoming the dogmas of Catholicism, scholastic philosophy and political loyalty to the Spanish monarchy. This article recreates the history of this newspaper.

Keywords: La Constitución Feliz, independence, journalism. 


\section{INTRODUCCIÓN}

En julio de 1810 ya existían en la Nueva Granada siete periódicos ${ }^{1}$ que registraban no solamente los principales hechos y la cultura de la vida cotidiana, sino también el pensamiento heterónomo de un puñado de ilustrados criollos, como Antonio Nariño, Camilo Torres, Jorge Tadeo Lozano, Francisco José de Caldas, Manuel del Socorro Rodríguez — considerado el padre del periodismo en Colombia-, quienes con Francisco Antonio Zea, Luis de Astigarraga, José Celestino Mutis, Fray José María Valdés, José María Gruesso, Francisco Antonio Rodríguez y el propio Simón Bolívar habían inoculado, conducido y liderado el germen emancipador a través de sus páginas.

Fue tan importante el periodismo en esta gesta que una vez suscrita el Acta de Independencia, al amanecer del sábado 21 de julio de 1810, "una de las primeras iniciativas de los entusiastas integrantes de la Junta Suprema del Nuevo Reino de Granada fue la de publicar un periódico que les sirviera de vocero" (Cacua, 1987: 53). Apareció, entonces, La Constitución Feliz, el 17 de agosto de 1810. La tarea de hacer tal y tan importante publicación la encomendaron a Manuel del Socorro Rodríguez, pues su experticia de haber publicado 265 ediciones de El papel Periódico de la Ciudad de Santa Fe de Bogotá, 48 de El Redactor Americano, 71 de El Alternativo del Redactor Americano, 1 de Últimas Noticias y 7 de Los Crepúsculos de España y Europa, así como su reputada imagen de hombre ilustrado, les ofrecía a los líderes revolucionarios no solamente la seriedad y la confianza, sino también la seguridad para hacer conocer a la opinión pública el discurso de la revolución.

Dos fenómenos se articularon en los procesos independentistas del Nuevo Reino de Granada: la imprenta y las ideas ilustradas de quienes configuraron esa relación entre independencia y periodismo.

1 Eran estos: Papel Periódico de la Ciudad de Santafé de Bogotá (1791); Correo Curioso, Erudito, Económico y Mercantil de la Ciudad de Santafé de Bogotá (1801); El Redactor Americano (1808); Alternativo al Redactor Americano (1809); Últimas Noticias (1809); Semanario del Nuevo Reyno de Granada (1808), y la Constitución Feliz (17-08-1810). 


\section{LA IMPRENTA}

Si bien la imprenta solo llegó al Nuevo Mundo un siglo después de su invención ${ }^{2}$, con la aparición de los primeros periódicos en 1785 (Aviso del Terremoto y Gaceta de Santa $\mathrm{Fe})^{3}$ comenzó a funcionar en el Nuevo Reino de Granada este descubrimiento que cambió la suerte del mundo, permitió al hombre salir de su ignorancia ${ }^{4}$ y a los criollos les fundamentó su libertad. La imprenta había sido inventada por el alemán Juan Gutemberg en 1450 y fue mejorada por Fust y Shöffer. Como novedad tecnológica se propagó muy rápidamente por Alemania, Italia, Suiza, Francia y España (1474). Irrumpió de tal manera que, como en el caso de España, fue acogida sin recelo y con toda libertad. Pero tanta libertad duró allí solo cincuenta años, pues los Reyes Católicos dictaron un reglamento sobre el ejercicio de imprenta y las precauciones que debían tenerse para su uso. Fue así como promulgaron la Pragmática del 8 de julio de 1502, para que no sufrieran ni la fe, ni la religión, ni las buenas costumbres. Con la Pragmática se inició la censura previa, a la cual se sumó también la establecida por el Tribunal de la Santa Inquisición: censura con pena de muerte.

En la Nueva Granada, los jesuitas fueron los encargados de dirigir la primera imprenta hasta su expulsión en 1767. Como su taller tipográfico desde esa fecha estaba improductivo, Antonio Espinosa de los Monteros, con algunos dineros que recibió del virrey, compró el taller y acondicionó la Imprenta Real. Esta produjo en 1778 un almanaque para ese año, con lo que se inició una nueva época para el taller de impresión, el cual fue ampliado con elementos llegados de Espańa, pues por decreto real se ordenó establecer una imprenta en Santa Fe, donde se publicaron desde novenas, hasta libros de derecho. Pero un nuevo grupo de publicaciones hizo su aparición con el antes mencionado Aviso del Terremoto: nacieron los periódicos, comenzó a oler a tinta la libertad.

2 El primer país al que llegó la imprenta fue México (1533); luego llegó a Perú (1581), Guatemala (1660), Paraguay (1680), Argentina (1705), La Habana (1707) y Santa Fe de Bogotá (1737).

3 Los dos primeros periódicos solo tuvieron dos y tres ediciones, respectivamente; por ello, se considera como inicio de la prensa en Colombia la aparición, el 9 de febrero de 1791, del Papel Periódico Ilustrado de Santa Fe de Bogotá, dirigido por el bibliotecario del virrey José de Ezpeleta, el cubano don Manuel del Socorro Rodríguez.

4 Para el siempre bien recordado historiador colombiano Germán Arciniegas, un segundo hito después de la invención de la imprenta, en el mismo siglo, también sacó de la ignorancia a los hombres: el descubrimiento de América. 


\section{LAS IDEAS ILUSTRADAS}

La Ilustración tradicionalmente se ha considerado como un movimiento intelectual y científico que se desarrolló durante el siglo XVIII, principalmente en Europa, a causa de, por un lado, los diferentes cambios socioeconómicos (la administración pública se ensanchaba, lo mismo que sucedía con el comercio y la industria; las ciudades europeas crecían demandando Estados más eficientes) y, por otro, el avance científico-técnico de la época.

El movimiento ilustrado se caracterizó por su visión crítica de la realidad, rasgo que se observa en el rechazo "racional" al marasmo suscitado en la época por los constructos religiosos de la verdad revelada (dogmas de la Iglesia católica), la tradición escolástica y la fidelidad a la monarquía, como únicas maneras de progreso. A partir de la Ilustración, la historia parece ser distinta: la construyen los propios individuos, pues ellos son los dueños de su autonomía. Los individuos, buenos por naturaleza, han venido a esta tierra a ser felices. Y esa felicidad, para que sea auténtica, debe estar basada en la propiedad privada, la libertad y la igualdad.

En Europa, sobre todo en Inglaterra y Francia (donde la Ilustración tomó el nombre de Enciclopedia), emergen los representantes del movimiento ilustrado. En el campo de la filosofía, Thomas Hobbes y John Locke, en Inglaterra, sustentan su teoría política de la monarquía desde dos riveras opuestas. Hobbes (1588-1679), con su Leviatán, defiende la monarquía absoluta, y Locke (1632-1704) defiende la monarquía limitada. Por otra parte, en Francia, los principales representantes de la Ilustración son Carlos Secondat, mejor conocido como el "Barón de Montesquieu" (1689-1785), propulsor de la división de poderes; François Marie Arouet, Voltaire (1694-1778), quien pregona la libertad política y la libertad religiosa; y Juan Jacobo Rosseau (1712-1778), precursor de la democracia, a partir de un contrato social. En el campo de la economía, aparecen los fisiócratas, una escuela francesa de pensamiento económico liderada por Francois Quenay (1694-1774) y Anne Robert Jacques, más conocido como Turgot (1727-1781).

Para esta escuela, la riqueza está asegurada sin mediación del gobierno, pues proviene de la tierra. En contraposición a la teoría fisiócrata francesa, desde Escocia aparece 
Adam Smith (1723-1790), quien en su Ensayo sobre la naturaleza y las causas de la riqueza de las naciones señala, argumenta y sostiene que la riqueza proviene del trabajo.

Emmanuel Kant (1724-1804), en diciembre de 1783, reflexiona y responde de manera directa a la pregunta hecha por un diario alemán: “¿Was ist Aufklärung?" (“¿Qué es la Ilustración?”). Y en el primer párrafo de su escrito deja ver una respuesta que no es meramente una definición, pero que tampoco es una mera opinión:

La ilustración es la salida del hombre de su minoría de edad. El mismo es culpable de esa minoría. La minoría de edad estriba en la incapacidad de servirse del propio entendimiento sin la dirección de otro. Uno mismo es culpable de esta minoría de edad cuando la causa de ella no yace en un defecto del entendimiento, sino en la falta de decisión y ánimo para servirse con independencia de él, sin la conducción de otro. jSapere Aude! ¡Ten valor de servirte de tu propio entendimiento! He aquí la divisa de la ilustración (Kant, s. f.).

\section{IMPRENTA E ILUSTRACIÓN}

Como se señaló en la presentación de este escrito, un grupo de criollos ilustrados comprendieron e hicieron posible el periodismo en el Nuevo Reino de Granada. En sus mentes rugía ese "iSapere Aude!”: ¡Ten valor de servirte de tu propio entendimiento", y se dieron a la tarea de recrear la realidad. Primero lo hicieron tímidamente con el Aviso del Terremoto, luego con la Gazeta de Santa Fé, y ya en propiedad con el El papel Periódico de la Ciudad de Santa Fe de Bogotá (1791), El Correo Curioso, Erudito, Económico y Mercantil de la Ciudad de Santafé de Bogotá (1801), El Redactor Americano (1808), El Alternativo al Redactor Americano (1809), Últimas Noticias (1809), Semanario del Nuevo Reyno de Granada (1808), Las Memorias (1810?-1811) y La Constitución Feliz (1810), nuestro objeto de análisis. 


\section{LA OPINIÓN PUBLICADA EN LA PRENSA EN LA CONFIGURACIÓN DE LA(S) IDENTIDAD(ES) NACIONAL(ES) EN COLOMBIA DURANTE EL PERIODO 1791-1810}

La opinión publicada como componente de la opinión política aparecida en los primeros periódicos es un hecho que merece la pena investigar desde la academia, con el propósito de explorar su incidencia en la configuración de la identidad de los colombianos, pues es conocido que hasta nuestros días la discusión ha sido si la opinión publicada trasciende o no la suma de opiniones individuales y si promueve el bien común; o si, por el contrario, se queda en la idea del "malentendido periodístico que consiste en identificar las posturas de los editorialistas y comentaristas de la información colectiva, en nombre de un público inasequible, con la opinión pública" (Ochoa, 2000: 8). Rosseau definía este tipo de opinión como la forma de representar la voluntad general; los utilitaristas, como el reflejo de la mayoría de individuos de una comunidad.

Desde los años cuarenta del siglo XX se ha optado por considerar la opinión pública como los resultados que arrojan los sondeos de opinión en grupos relativamente delimitados de individuos; sin embargo, como lo afirma Ochoa (2000), según la ubicación de los emisores y receptores, la opinión pública bien puede ser la opinión del público, la opinión pública publicada, la opinión de quienes buscan un interés público, la opinión de los hombres públicos, el debate sobre el sector público, la opinión sobre asuntos de interés público y la opinión pública en la actualidad.

Este panorama justifica este tipo de investigación sobre la génesis de la prensa en Colombia; una investigación que ha llevado a analizar e interpretar la realidad con el propósito de transformarla hacia la búsqueda de la libertad; la misma que, cuando se creyó alcanzada, fue divulgada, pregonada y analizada en hechos históricos que incidieron de alguna manera en la construcción de la identidad nacional:

La identidad no es pues lo que se le atribuye a alguien por el hecho de estar aglutinado en sentido y valor a la vida del individuo. Es al tornarse expresiva que la identidad depende de, y se constituye en, el reconocimiento de los otros: intercambio en el que los individuos y grupos se sienten despreciados o reconocidos por los demás (Martín-Barbero, 2001: 26). 


\section{EL PROBLEMA}

La pregunta a la que quiere darse respuesta es esta: ¿cómo ha incidido la opinión publicada en los primeros periódicos colombianos (1791-1810) en la configuración de la identidad nacional? Dar respuesta a esta pregunta invita a reconocer, en los contenidos de los primeros periódicos publicados Colombia entre el periodo 17911810, las ideas libertarias y examinar los principales rasgos de opinión que han incidido en la identidad nacional.

Ahora bien, conviene señalar la presentación del curso doctoral Identidad e Identidades, de reciente desarrollo en la Universidad Santo Tomás:

La identidad ha tenido un lugar central en el pensamiento filosófico latinoamericano, desde el denominado "descubrimiento" o "encuentro de dos mundos", hasta nuestros días. En este decurso histórico, la filosofía latinoamericana y la historia de las ideas han asumido como tarea central la dilucidación de lo más propio, del rango esencial del ser latinoamericano y la comprensión de nuestro propio ethos, de nuestro propio modo de ser. En América Latina, según Leopoldo Zea, el problema de la identidad se encuentra estrechamente relacionado con el proyecto y el proceso histórico de integración (Arocena y Antolínez, 2010).

Por ello, la propuesta investigativa se desarrollará, para buscar "dilucidar lo más propio”, desde cinco ejes temáticos o problemas, con el propósito de observar su abordaje por parte de la prensa de la época y analizar la conformación de la identidad nacional: 1) el problema ético, 2) el problema de género, 3) el problema del indio y del negro, 4) el problema social y político, 5) el problema del medio ambiente.

\section{Metodología}

El alcance de esta investigación es interpretativo con enfoque cuali-cuantitativo, pues: 1) observará, analizará y evaluará el fenómeno de la opinión publicada de los periódicos del Nuevo Reino de Granada entre 1791 y 1810; 2) establecerá las suposiciones o ideas 
que emanen de lo anterior, así como su fundamentación y revisión en la construcción de la identidad como proyecto histórico; 3) será propositiva a partir de las observaciones, al crear foros de discusión y diálogo (como el club de lectura de donde parte este trabajo), que permitan reconstruir o afirmar la identidad de la sociedad actual nacional.

\section{LA PRENSA COMO VOCERA DE LA REVOLUCIÓN: LA CONSTITUCIÓN FELIZ}

La Constitución Feliz es el nombre del periódico que la Junta Suprema del Nuevo Reino de Granada solicitó que se editara para que fuera vocero de la firma del Acta de Independencia y todo lo que en adelante viniera. Lo tenía todo para ser feliz: la imprenta como su cuna, la ilustración como su lenguaje, y al mejor, al más ilustrado y experimentado de los periodistas de la época como su hacedor.

En el cabezote del periódico se señala que la publicación está enfocada a dos grandes áreas: la política y la economía del Nuevo Reino de Granada. Como en la época no existía aún la sociología como ciencia, los estudios, la descripción y análisis de las relaciones de individuos en su realidad, desde estas dos variables, compensaban esta carencia. Sin embargo, en el "Prospecto" de La Constitución Feliz, que es la primera información dirigida de manera directa a los lectores de los periódicos de la época, Manuel del Socorro Rodríguez señala dos caminos: el primero con un epígrafe en el que plasma una frase en latín del Libro IV de La República de Platón: "Religio vera est firmamentum reipublice", que quiere decir: "La verdadera religión es la base de la República”. El segundo camino lo señala más adelante en el mismo prospecto, cuando afirma:

Si los gobiernos establecidos por título de conquista son respetados y obedecidos de los hombres, ¿̨cuánto más deberán serlo aquellos que establecen la razón y la sabiduría para desagraviar la Divina Religión, asegurar la legítima soberanía, abolir el despotismo, honrar la humanidad y perpetuar el bien común? No ha sido esta una obra del capricho humano, sino del poder Divino, si bien se examina por todos sus aspectos; y por tanto debe anunciarse a todos los pueblos por medio de una descripción circunstanciada. 
Como artículo de fondo, en la "Relación sumaria instructiva" procede con el desarrollo del hecho: "Las novedades ocurridas en la M. N. y M. L. ${ }^{5}$ Ciudad de Santafé de Bogotá, Capital del Nuevo Reino de Granada, desde la tarde del 20 de julio de 1810, hasta el día de la fecha (17 de agosto de 1810)". Antes de hincar su crónica, el periodista hace su profesión de fe y enfatiza su postura ética sobre lo que vio y presenció, con "la verdad, la imparcialidad, la sana política, la buena crítica, la sencillez y la buena fe, [sobre] el incidente que decretaría la libertad de la ciudad y todo su reino y la mutación de un gobierno tiránico y opresor":

La tarde del viernes 20 de julio, día de Santa Librada, era esperado el S. D. Antonio Villavicencio, comisionado regio, por lo cual se encomendó a algún patriota se encargara del adorno de las mesas, quien le solicitó a un español europeo, prestado un ramillete y a cambio respondió con expresiones injuriosas contra todos los españoles americanos. Este hecho sucedió en la Calle Real. Rápidamente este incidente se propagó entre los patriotas de toda clase y condición, lo que produjo un solo grito común que decía "Mueran los malos españoles y vivan los buenos", y apresaron al agresor y a otros espańoles europeos.

\section{Y continúa narrando:}

El sabio senado supo defender su pueblo fiel y se opuso frente a los tiranos, esa misma noche casi todos los americanos se armaron para defender su patria. Se inició entonces la formación de la Suprema Junta Gobernativa con el apoyo popular, los curas de las parroquias y prelados de las religiones; es así como la noche del 20 de julio de 1810 fue el principio de un gobierno sabio, justo y digno de la fidelidad americana [...

Y tú, oh dulce y encantadora elocuencia, rompiendo las cadenas de la cruel esclavitud en que yacías oprimida, recobraste en un momento tu imperio majestuoso, haciendo ver que la ilustre América es también madre fecunda de sabios Demóstenes y Cicerones. Ah! Cómo pudiera yo insertar aquí elocuentísimos discursos por la multitud y gritería, pero bella y feliz por los grandes aciertos que en ella se admiraron.

5 Abreviaturas que significan "muy noble y muy leal" (N. del E.). 
Finalmente, el pueblo y los señores vocales formaron la resistencia contra el tiránico despotismo, se dividieron en cuadrillas para recorrer las calles y evitar desórdenes y para que los vocales de la Junta congregados en la Plaza Mayor pudieran obrar sin recelo. Y siguieron llegando más pueblos vecinos para apoyar la lucha: el corregidor del pueblo de Bosa, Antonio Sornosa, junto con nueve pueblos que comprendían su jurisdicción, y el curato de Bosa, D. D. Juan Joseph Porras, con los hacendados de los contornos de la ciudad: "Y así llegó el amanecer del 21 de julio, día nuevo y faustísimo para la religión, la paz, la justicia y la libertad. Día de la eterna memoria”.

Se instaló la Suprema Junta del Nuevo Reino de Granada, en nombre y obediencia del amadísimo Fernando VII, y se procedió a la captura de los ministros y funcionarios públicos que obraron con mala fe y gobernaron con despotismo y arbitrariedad. Asimismo, se dejó en libertad al canónigo magistrado señor Andrés Rosillo, aclamado vocal de la Junta por todos, y entre víctores y aclamaciones lo condujeron a la plaza mayor, después de seis meses de arresto.

Al siguiente día, el 23 de julio, se publicó el "Bando de instalación y buen gobierno". El 25 de julio, día del apóstol Santiago, se "ponen en seguridad" con respeto y consideración al ex virrey teniente general Antonio Amar y a muchas personalidades del gobierno anterior. Y el 29 se publica la proclama o convocatoria circular, dirigida a todas las provincias del reino. Este mismo día se celebró una ceremonia de acción de gracias, con la asistencia del clero secular y regular, los colegios, los empleados públicos, los cuerpos militares, la nobleza y la plebe.

El periodista enaltece los sentimientos generosos y compasivos de su pueblo sensible y virtuoso, que se olvidó de la tiránica opresión en la que había vivido, acordándose lo que la santa religión profesa, demostrando clemencia por los enemigos de la libertad que estaban siendo expulsados de la ciudad.

Finalmente, escribe sobre cómo el anterior gobierno se negó siempre a convocar un cabildo abierto o a reconocer la Suprema Junta, y habla de la importancia no solo de saber y conocer todos estos hechos, sino de poder reflexionar sobre lo que el reino ha sufrido. También habla de la unión de todos por lograr su libertad y del apoyo de tanta gente que colaboró para que no faltaran víveres en esa revolución tan acalorada, 
o de los pueblos vecinos que vinieron en su apoyo dispuestos a defender los sagrados derechos de libertad. Igualmente informa cómo quedó organizada la Nueva Junta Suprema y da a conocer el nombre de cada uno de los vocales que la componen.

La crónica periodística por la que Manuel del Socorro Rodríguez optó para contar el hecho del 20 de julio y los posteriores hasta el 17 de agosto tiene los matices que imprimieron a las suyas los cronistas de Indias, es decir, la narración del hecho con detalles; pero igualmente los de la crónica literaria, pues no demanda tensión dramática.

\section{Colofón}

Durante el siglo XIX, se produjeron en la Nueva Granada en particular y en América Latina en general diversos cambios de orden político, económico y social. La gran mayoría de las colonias desarrollaron procesos de independencia de la Corona española, pero en realidad simplemente se pasó de una forma de dominio externo a un dominio interno, con las herramientas traídas de afuera: la lengua, la ética cristiana, la nueva cultura. Esto se hace evidente en el relato de Manuel del Socorro Rodríguez en el periódico La Constitución Feliz, donde señala que la independencia fue posible por el poder divino y niega la intervención humana en él. He aquí tres ideas sobre el particular:

1. El problema del no ser para los "descubiertos" — que se originó, primero, con el descubrimiento y, luego, con la conquista - se quiso solucionar con el ser que la independencia pretendía ofrecer. Pero este nuevo ser los criollos no lo tenían claro, pues no era el mismo que se había perdido y que ahora se pretendía rescatar. Este era un nuevo ser construido a partir de la fusión de ideas propias y extrańas: entre las primeras figuraron las ideas raizales de organización y de cultura; entre las segundas estaban aquellas resultantes de las revoluciones liberales emanadas de la Revolución francesa. Por ello, la razón de ser del periódico: se necesitaba difusión sobre el nuevo horizonte que se cernía.

2. Este proceso generó, además, un nuevo orden y comportamiento. El hombre latinoamericano, por ejemplo, pasó de tener una propiedad colectiva a tener una propiedad individual. Un nuevo orden que trajo consigo una pulsión no solamente ética, sino también económica: lo privado en contra de lo colectivo (Cacua, 1987). 
Ya su norte se lo habían cambiado por el oriente, y su sur, por el occidente. De manera análoga, las relaciones sociales se tornaron distintas: la relación social se tornó en relación política; y la relación con los dioses pasó de ser una interacción múltiple con la naturaleza, para tornarse en temor teológico con un solo dios. Igual sucedió con los factores de esa relación con la naturaleza, relación poiética: los insumos, los productos y los símbolos originaron el mercado y el comercio.

3. Las ideas liberales penetraron tenuemente en el continente, pero se impuso de manera importante una mezcla entre lo novedoso de las ideas liberales con el reducto de las ideas medievales. En el periódico de don Manuel se evidencia.La Constitución Feliz, de la cual se publicó solo una edición, encontró pronto su infelicidad, pues fue sustituida a los diez días por el Diario Político de Santa Fe de Bogotá. A partir de allí, la vida de la prensa tuvo un agitado devenir, no solo por las contingencias políticas provinciales y el constitucionalismo de allí emanado, sino por las ideologías políticas, sociales y económicas provenientes de Europa, al igual que por los tires y aflojes entre centralistas y federalistas. El siglo XIX apenas comienza; muchas serán sus pulsiones, pero dejará una abundante y compleja red de constituciones en todos los países de América Latina, felices unas, como el nombre del periódico, e infelices otras.

\section{REFERENCIAS}

Alberdi, J. B. (s. f.). Ideas para presidir a la confección de un curso de filosofía contemporánea. Recuperado de http://www.ensayistas.org/antologia/XIXA/alberdi/

Arciniegas, G. (1979). NuestraAméricaesun ensayo. Cuadernosde Cultura Latinoamericana. Recuperado de http://es.scribd.com/doc/35730054/Nuestra-America-es-un-ensayo-Arciniegas

Arciniegas, G. (2004). El continente de los siete colores. En Historia de la cultura en América Latina. Bogotá: Taurus.

Bushnell, D. (2007). Colombia, una nación a pesar de sí misma (6. ${ }^{\mathrm{a}}$ ed.). Bogotá: Planeta.

Cacua, P. A. (s. f.). La imprenta en Colombia. Bogotá: Fundación Universitaria Los Libertadores. 
Cacua, P. A. (s. f.). Historia de la prensa en Colombia. Bogotá: Fundación Universitaria Los Libertadores.

Cacua, P. A. (1985). Don Manuel del Socorro Rodríguez, fundador del periodismo colombiano. Bogotá: Instituto Colombiano de Estudios Latinoamericanos y del Caribe, Universidad Central.

Cacua, P. A. (1987). Libertad y responsabilidad de la prensa. Bogotá: Fundación Universitaria Los Libertadores.

Foucault, M. (2007). La arqueología del saber (23. ${ }^{a}$ ed.). Madrid: Siglo XXI.

Kant, I. (s. f.). Qué es la Ilustración. Recuperado de https://docs.google.com/document/d/ 10b2teqe2g_-7t59gtmqim0jt0ytznox6kqandfcf_g8/edit?hl=en_us\&pli=1

Mardones, J. M. (2005). Filosofía de las ciencias humanas y sociales (3. ${ }^{\mathrm{a}}$ ed.). Bogotá: Antrophos.

Marquinez Argote, G. (comp.) (1981). ¿Qué es eso de... filosofía latinoamericana? Introducción al filosofar. Bogotá: El Búho.

Marquinez Argote, G. et al. (1993). La Filosofía en América Latina. Historia de las ideas. Bogotá: El Búho.

Martí, J. (1997). Politica de Nuestra América. México: Siglo XXI.

Martín-Barbero, J. (2001). Reconfiguraciones de lo público y nuevas ciudadanías. Anàlisi, 26, 71-88.

Ochoa, Ó. (2000). Comunicación politica y opinión pública. México: McGaw-Hill.

Otero Muñoz, G. (1998). Historia del periodismo en Colombia. Bogotá: Universidad Sergio Arboleda.

Paul, R. y Elder, Linda. (s. f.). Cómo leer un párrafo. Recuperado de http://www.criticalthinking.org/resources/PDF/SP-Como_Leer_un_Parrafo.pdf 
Campos en Ciencias Sociales

Comunidad, acción y comunicación

Restrepo, J. D. (2004). Como el zumbido al moscardón. Bogotá: Fondo de Cultura Económica.

Restrepo, J. D. (2006). Cuarenta lecciones de ética. Caracas: Debate.

Ron, F. (2004). Cómo sacar provecho a la lectura. Bogotá: Círculo de lectores.

Zuleta, E. (2001). Elogio a la dificultad y otros ensayos (5. a ed.). Cali: Fundación FEZ. 